RU Тэффи: роль псевдонима в перцепции женского творчества русского модернизма

\author{
Ким Ю. В.
}

Аннотация. Цель исследования - определить роль формирования псевдонима русской писательницы Н. А. Тэффи в перцепции женского творчества в первой трети ХХ в. В статье проясняются мотивы выбора псевдонима и выявляются механизмы его формирования. Научная новизна исследования заключается в анализе интертекстуальных связей псевдонима Тэффи с британской литературой и культурно-лингвистической средой. В результате доказано, что аллюзивность псевдонима Тэффи является намеренной мистификацией, ретроспективно созданной для запечатления особого отношения к женскому творчеству в русском модернизме.

\title{
Teffi: Pseudonym Role in Perception of Female Creativity in the Russian Modernism
}

\begin{abstract}
Kim Y. V.
Abstract. The study aims to determine the role of the pseudonym formation of the Russian writer N. A. Teffi in perception of women's creativity in the first third of the XX century. The article clarifies motives for choosing the pseudonym and identifies mechanisms of its formation. Scientific novelty of the study lies in analysing intertextual connections of the pseudonym Teffi with the British literature and cultural and linguistic environment. As a result, it is proved that allusiveness of the pseudonym Teffi is a deliberate hoax retrospectively created to capture specific attitude towards women's creativity in the Russian modernism.
\end{abstract}

\section{Введение}

Актуальность темы исследования обусловлена возрастающим интересом к концепциям феминности и конструированию гендера в современном обществе. Начиная с конца XIX в. социальное положение женщины и формы его репрезентации претерпели значительные изменения. Н. А. Тэффи, одна из ярких представителей русской литературы первой половины XX в., безусловно, внесла значительный вклад в то, как литература и искусство того времени отражали изменившуюся социокультурную реальность. Роль псевдонима писательницы здесь не может быть переоценена. Несомненно, этот факт не остался незамеченным исследователями: многие видные литературоведы не раз комментировали роль мистификации и жизнетворчества в биографии писательницы. Следует сказать, что специалисты по-разному оценивают степень случайности в выборе псевдонима. Поэтому вопрос о литературных и культурных аллюзиях, намеренно заложенных Н. А. Тэффи в своем творческом имени, остается дискуссионным и представляет существенный интерес для литературоведов.

Для достижения указанной цели исследования необходимо решить следующие задачи: во-первых, прояснить роль выбора мужского псевдонима предшественницами и современницами Тэффи; во-вторых, выявить отношение к проблеме женского творчества самой Тэффи; в-третьих, проследить литературные и социокультурные аллюзии в рассказе «Псевдоним», раскрывающие положение русской женщины-писательницы.

Для осмысления творческого наследия Н. А. Тэффи в статье применяются социокультурный, биографический, интертекстуальный методы исследования, а также сравнительно-сопоставительный подход и техники пристального чтения.

Теоретической базой исследования, наряду с трудами российских литературоведов, послужили публикации зарубежных исследователей Иф Кософски Седжвик [8] и Клаудии Розенхан [10], в которых рассматриваются концепции феминности и проблемы конструирования гендера в европейской литературе.

Практическая значимость настоящего исследования заключается в том, что раскрываемые в статье литературные и социокультурные аллюзии псевдонима Тэффи могут быть использованы в научно-педагогической деятельности для иллюстрации гендерной перцепции и интертекстуальности русского модернизма. 
Выбор мужского псевдонима как общеевропейская традиция литературы XIX в.

В своем рассказе «Псевдоним», написанном уже в эмиграции в 1931 г., Надежда Александровна объясняет происхождение своего звучного литературного имени. С первых же строк Тэффи сравнивает свой псевдоним с «собачьей кличкой» [6, с. 68] и называет его «англизированным словом» [Там же]. Любопытно, что писательница подчеркивает несоответствие этой номинации своей идентичности - русская пишущая женщина, тем самым заставляя задуматься о возможных парах антитез «русская-английская», «женщина-собака (т.е. не человек)». Далее Тэффи противопоставляет свой псевдоним более звучным мужским писательским именам «Максим Горький», «Демьян Бедный», «Скиталец» [Там же]. С одной стороны, в этом кроется напускное жеманство ироничной женщины, но, с другой, - в этом противопоставлении можно увидеть аккуратную попытку отразить перцепцию женского творчества в России первой трети прошлого века. Выбор мужского псевдонима, по мысли самой писательницы, - «умно, осторожно и красиво», а женское творчество, да еще под собачьей кличкой - «что за ерунда?» [Там же].

Здесь невольно вспоминается уже к тому времени сложившаяся традиция европейской литературы; женщины-писательницы нередко выбирали себе мужские имена: сестры Бронте, скрывавшиеся под псевдонимом Каррер, Эллис и Эктон Белл (напомним, что роман Анны Бронте «Незнакомка из Уайлдфелл-Холла» 1848 г. считается одним из первых феминистских романов Европы), Мэри Энн Эванс и ее псевдоним Джордж Элиот, Амандина Аврора Люсиль Дюпен, она же Жорж Санд и т.д. Мотивы этих женщин были понятны: рукопись под мужским именем скорее примут в издательство, женское писательство не было общепринятым (сам факт наделения акта писательства гендерной детерминацией уже говорит о предвзятом отношении к женщинамавторам), а сами писательницы высмеивались. В частности, это предвзятое отношение было воплощено в гротескном, карикатурном образе «синего чулка» в Викторианской Англии.

Русская общественная мысль второй половины XIX в. не меньшим образом критиковала возможность предоставления женщинам социальных ролей за пределами замужества и материнства. Как пишет современная исследовательница проблем гендера Е. И. Трофимова, «пренебрежительное отношение к женщине, соответственно, принижает и сферы женской деятельности» [5, с. 183], а значит, вынуждает женщин-писательниц скрывать свою идентичность за мужским псевдонимом.

\section{Отношение Тэффи к проблеме женского творчества}

Тэффи словно бы «переламывает» эту европейскую традицию: несомненно осознавая критическое отношение к женскому творчеству, она намеренно не берет мужской псевдоним. На первый взгляд, Надежда Александровна наделяет свое творческое имя исключительно игровой функцией. Жива Бенчич в статье «Псевдоним (имя и “идентитет”)» называет такие псевдонимы «депрагматизированными», то есть такими, «которые не являются следствием какого-либо внешнего, социального, или внутреннего психологического давления - напротив, они образованы по имманентным законам эстетической игры» [1, p. 126]. Здесь нужно заметить, что в России рубежа XIX-XX вв. действительно складывается новая творческая парадигма, в которой женщины обретают собственный голос и все чаще составляют конкуренцию авторам-мужчинам. Как справедливо отмечает известный дореволюционный критик В. Чуйко, «никогда в русской литературе не было так много женщин-писательниц, как в настоящее время. <... Писательница с именем, журналистка, сотрудница газеты, переводчица - далеко не редкое явление в русском обществе» [7, с. 23, 26]. Положим, Надежде Александровне на заре своей творческой карьеры уже не нужно было искать псевдоним, скрывавший ее гендер, настолько прогрессивна была русская общественность первых лет XX в. Но, несмотря на свою распространенность, женское творчество все также становится объектом критических нападок и гендерных предрассудков. Так, например, распространенной была мысль об имманентной вторичности и недостаточной гениальности женского творчества: «...природа уделяет женщинам искру таланта, но никогда не дает гения» [3, с. 22]. Увы, эти традиционные представления о превосходстве мужского интеллекта над женским не обошли стороной женщин-писателей Серебряного века. Так, например, Зинаида Гиппиус, женщина, известная своим острым умом и самостоятельным характером, тем не менее подписывала свои колкие литературно-критические статьи вымышленным мужским именем Антон Крайний. Напомним, что сто лет назад женщины-писательницы все еще были вынуждены испытывать на себе шовинистическое давление преобладающей мужской аудитории. Так, великий русский поэт ХХ в. Осип Мандельштам писал в 1922 г. о том, что «“мужской силы и правды” иногда достигает только поэзия Аделины Адалис» [2, с. 275].

Следовательно, невозможно говорить о только лишь игровом характере имени Тэффи. Безусловно, особенность псевдонима Тэффи заключается в намеренном снижении его литературного пафоса за счет уподобления собачьей кличке. Однако, на наш взгляд, в семе «Тэффи» есть еще несколько значимых элементов, позволяющих говорить не просто о сниженности, но и о своеобразном феминистическом повороте, произошедшем в русской литературе модернизма. Ведь, по признанию самой писательницы, «прятаться за мужской псевдоним не хотелось» [6, с. 69]. Очевидно, что Тэффи не скрывает свою идентичность за шутливым псевдонимом, но деконструирует само отношение к феномену женщина-писательница в России первой трети прошлого века. Смеем утверждать, что псевдоним Тэффи - скорее умный литературный ход, культурно осознанный жест, чем случайный набор благозвучных слогов. 


\section{Литературные и социокультурные аллюзии в рассказе «Псевдоним»}

Начнем с того, что «Тэффи» в интерпретации Надежды Александровны - это не просто собачья кличка, нечеловеческое/немужское имя, но и производное от «Стеффи», домашнего имени некого Степана, «отменного дурака», по замечанию писательницы [Там же]. Можно сделать вывод, что Тэффи, понимая несостоятельность женского творчества в глазах общественности, вынуждена брать мужской псевдоним. Но вместо публичного мужского имени она выбирает некий домашний дистиллят, слабую смесь мужественности и интеллектуальности. Таким образом, женщина-писательница как будто сравнивается с глупым, домашним мужчиной, обыгрывая бытовавшие стереотипы о женском семейном предназначении и неспособности женщин к умственному труду (расхожее мнение о том, что мозг женщины меньше мозга мужчины, упоминается в пьесе Тэффи «Женский вопрос»). Можно предположить, что женщина-писательница в русском обществе начала прошлого века - это такой же одиозный и смешной персонаж, как некий Стеффи, отменный дурак. Увы, нам ничего неизвестно о семейном положении Стеффи, но его связь с домашним кругом позволяет наделить его образ чертами вытесненной гомосексуальности. Этот феномен был хорошо описан Иф Кософски Седжвик в книге «Эпистемология чулана». Как замечает исследовательница, «холостяк занимает промежуточное положение между домашним женским пространством и внесемейным, политическим, экономическим мужским миром. Неминуемый интерес к женским делам и домашним заботам не в последнюю очередь феминизирует его образ (хотя в то же самое время холостяк получает доступ в мужской мир благодаря личным связям с завсегдатаями клубов и богемой)» [8, p. 189-190]. Холостяк становится своего рода алиби, позволяющим мужчине не жениться и при этом обладать неким социальным статусом. Но одновременно этот статус неустойчив и сомнителен; холостяка преследуют подозрения в немужественности, гомосексуальности и импотенции. Сравним эти подозрения в ненормативности с предрассудками в отношении разведенной творческой женщины, о которых иронично пишет сама Тэффи в рассказе «Демоническая женщина».

Характерно, что слово «Тэффи» в британской культуре само по себе ненормативно. Тэффи - оскорбительное английское прозвище валлийцев, по одной из версий, произошедшее от названия реки Тафф, на которой расположен Кардифф. Здесь можно вспомнить ту самую английскую расистскую песенку, получившую распространение в конце XIX в., которую цитирует писательница в своем рассказе:

Taffy was a Welshman, Taffy was a thief,

Taffy came to my house and stole a leg of beef.

I went to Taffy's house, Taffy was in bed,

I picked up a pocker and hit him on the head [9, p. 15].

В этом, на первый взгляд, по-детски шутливом четверостишии кроется сразу несколько культурных стереотипов Англии: (1) валлиец - по умолчанию вор, преступник, недостойный член общества, который врывается в чужие дома; (2) валлиец - лентяй и лежебока (удивительным образом этот предрассудок уживается с устойчивым образом валлийца-шахтера); (3) англичанин по праву может входить в дом к валлийцу и чинить жестокую расправу (здесь, видимо, легитимизуется многовековая история жестокого подавления валлийского населения англичанами). Для понимания, насколько Кимрофобия (Cymrophobia), ненависть англичан к валлийцам, была распространена в начале прошлого века, можно обратиться к книжке “The Perfidious Welshman” (1910 г.), где среди прочего содержатся такие унизительные и оскорбительные высказывания:

"Wales has no great women of good repute";

"No people were ever less fitter to call a country their own and themselves a nation than the Welsh" [Ibidem].

Таким образом, позволим себе провести аналогию между дураком «Тэффи» Степаном, Тэффи-валлийцем и Тэффи женщиной-писательницей. Все три Тэффи по разным причинам объединены качеством неполноценности, возможно даже порочности и преступности, и противопоставлены нормативному мужчине, умному, достойному и благопристойному. Мотив преступности, виновности женщины-писательницы, кстати, прослеживается в рассказе. Надежда Александровна боится, что ее будут искать с полицией, поэтому является в театр, где идет репетиция ее пьесы. На следующий день после успешной премьеры во время интервью Тэффи внутренне ликует: «Я спасена!» [6, с. 75], когда журналист словно бы находит для нее «алиби», утверждая, что ее псевдоним взят из Киплинга, а вовсе не имя дурака. Тут же Тэффи вспоминает и про английскую песенку, цитируя строки «Тэффи был валлийцем, Тэффи был вором», которые она якобы прочитала в романе «Трильби» английского писателя Джорджа Дюморье.

Однако, на наш взгляд, в псевдониме Тэффи содержится не только закодированный образ культурного гендерного подавления, но и своеобразное разрешение устойчивой ситуации, в которой женщинамписательницам приходилось испытывать чувство вины и стыдливо прятаться за мужские псевдонимы. Характерно, что в рассказе «Псевдоним» Таффи Киплинга и вор-валлиец служат для автора не столько литературными аллюзиями, сколько литературными подтверждениями правомерности творчества Надежды Александровны. Однако премьера «Женского вопроса» состоялась в 1907 г., уже позже дебюта Тэффи под своим псевдонимом, а в романе Дюморье «Трильби» (русские переводы романа вышли в 1896-1897 гг.) хоть и есть персонаж Тэффи, но вот цитируемой песенки про валлийца нет. Как пишет Д. Д. Николаев, «очевидная фактическая неточность позволяет усомниться в правомерности использования художественного текста в качестве 
документального свидетельства, тем более что собственная биография всегда была для Тэффи источником мистификаций» [4, с. 253]. Очевидно, что рассказ Тэффи лишь притворяется реконструкцией истории создания псевдонима, являясь на самом деле скорее деконструкцией перцепции женского творчества в русском обществе первой трети прошлого века. Таким образом, Тэффи в своем рассказе «Псевдоним» не столько перечисляет возможные версии происхождения имени, сколько интерпретирует образ русской женщиныписательницы в литературе русского модернизма. И здесь, на наш взгляд, отсылка к Киплингу, единственная литературная подсказка, не вымышленная Надеждой Александровной, имеет решающее значение в понимании новой роли женщины-писательницы.

Имя Таффи действительно используется Киплингом в его рассказе «Как было написано первое письмо» 1902 г. В отличие от Стеффи и валлийца из песенки, Таффи Киплинга - женское имя, его носит маленькая девочка, автор первого письма в первобытном мире, где, как ни странно, уже бытуют патриархальные порядки (сравним почтенное имя отца «Человек-ноги-которого-никогда-не-спешат» и менее добропорядочные имена матери «Женщина-которая-задает-слишком-много-вопросов» и девочки «Девочка-которую-нужнохорошенько-отшлепать-за-то-что-она-такая-шалунья»).

Очевидно, что киплинговское воплощение первого пишущего человека с помощью женского персонажа трактуется Тэффи, женщиной-писательницей, как своеобразное литературное зеркало, в котором отражается не только заслуживающий внимания феномен женского авторства, но и стереотипы, связанные с ним. По словам британского литературоведа Клаудии Розенхан, «пусть даже идея стратифицированных гендерных ролей в буквальном смысле сформулирована мужчинами, тем не менее миф о женской интеллектуальной неполноценности увековечен не только в понимании мужчин, но и в молчаливом принятии женщинами своей социальной роли» $[10$, p. 111]. Очевидно, что Н. А. Тэффи в своем рассказе «Псевдоним» предпринимает своеобразную попытку заявить о себе, чем нарушает устоявшуюся в европейской литературе традицию молчаливого принятия. На наш взгляд, уникальность и значение имени Тэффи как метонимии всей ее писательской деятельности заключаются именно в этом вербальном неприятии своей социальной роли, артикулированном через свой, лишь на первый взгляд шутливый, псевдоним.

\section{Заключение}

Подводя итог нашему исследованию, необходимо подчеркнуть, что доэмигрантское творчество Тэффи носило преимущественно шутливый и ироничный характер. Однако ретроспективный взгляд автора на собственную писательскую инициацию позволяет нам прийти к следующим выводам: сниженные (Стеффи-дурачок, вор-валлиец) и одновременно возвышающие образы (Таффи Киплинга) составляют сложное единство творческого имени, чей пафос далеко за пределами только лишь комичности псевдонима Надежды Александровны. Проблема выбора псевдонима предлагает несколько стратегий, отражающих модус творчества писательницы. Выбирая между сокрытием «идентита», его эстетизацией и раскрытием особенностей своей творческой личности, Надежда Александровна выбирает последнее, подчеркивая значение своей писательской судьбы в литературе Серебряного века. Имя Тэффи, помимо игровой, шутливой функции, выполняет также функцию характеризации своего владельца. Пишущая женщина, одновременно приниженная своим социальным статусом, но вознесенная своим творчеством - вот, на наш взгляд, истинное значение псевдонима Тэффи.

Перспективы дальнейшего исследования проблемы мы видим в более детальном изучении влияния британской литературы на творчество Н. А. Тэффи, а также перцепции женского авторства в литературе русского модернизма.

\section{Источники | References}

1. Бенчич Ж. Псевдоним (имя и «идентитет») // Russian Literature. 2001. XLIX. North-Holland. P. 115-128.

2. Мандельштам О. Сочинения: в 2-х т. М.: Худож. лит., 1990. Т. 2. Проза. 464 с.

3. Пономарев С. И. Наши писательницы. СПб.: Тип. Имп. акад. наук, 1891. 78 с.

4. Творчество Н. А. Тэффи и русский литературный процесс первой половины ХХ века. М.: Наследие, 1999.348 с.

5. Трофимова Е. И. Терминологические вопросы в гендерных исследованиях // Общественные науки и современность. 2002. № 6. С. 178-188.

6. Тэффи Н. А. Черный ирис. Белая сирень. М.: Эксмо, 2006. 448 с.

7. Чуйко В. Современные женщины-писательницы // Наблюдатель. 1889. № 4. С. 23-50.

8. Kosofsky E. S. Epistemology of the Closet. Berkeley - Los Angeles: University of California Press, 1990. 258 p.

9. Parker M. Neighbours from Hell? - English Attitudes to the Welsh. Tal-y-bont: Y. Lolfa, 2007. 176 p.

10. Rosenhan C. All Her Faculties: The Representation of the Female Mind in the Twentieth-Century English Novel. Berlin: Peter Lang, 2014. 227 p.

11. Бенчич Ж. Псевдоним (имя и «идентитет») // Russian Literature. 2001. XLIX. North-Holland. P. 115-128.

12. Мандельштам О. Сочинения: в 2-х т. М.: Худож. лит., 1990. Т. 2. Проза. 464 с.

13. Пономарев С. И. Наши писательницы. СПб.: Тип. Имп. акад. наук, 1891. 78 с.

14. Творчество Н. А. Тэффи и русский литературный процесс первой половины ХХ века. М.: Наследие, 1999. 348 с. 
15. Трофимова Е. И. Терминологические вопросы в гендерных исследованиях // Общественные науки и современность. 2002. № 6. С. 178-188.

16. Тэффи Н. А. Черный ирис. Белая сирень. М.: Эксмо, 2006. 448 с.

17. Чуйко В. Современные женщины-писательницы // Наблюдатель. 1889. № 4. С. 23-50.

18. Kosofsky E. S. Epistemology of the Closet. Berkeley - Los Angeles: University of California Press, 1990. 258 p.

19. Parker M. Neighbours from Hell? - English Attitudes to the Welsh. Tal-y-bont: Y. Lolfa, 2007. 176 p.

20. Rosenhan C. All Her Faculties: The Representation of the Female Mind in the Twentieth-Century English Novel. Berlin: Peter Lang, 2014. 227 p.

\section{Информация об авторах | Author information}

RU Ким Юлия Витальевна ${ }^{1}$, к. филол. н.

${ }^{1}$ Финансовый университет при Правительстве Российской Федерации, г. Москва

EN Kim Yulia Vitalievna ${ }^{1}, \mathrm{PhD}$

${ }^{1}$ Financial University under the Government of the Russian Federation, Moscow

${ }^{1}$ YVKim@fa.ru

Информация о статье | About this article

Дата поступления рукописи (received): 23.03.2021; опубликовано (published): 31.05.2021.

Ключевые слова (keywords): Н. А. Тэффи; псевдоним; русский модернизм; женский вопрос; N. A. Teffi; pseudonym; Russian modernism; women's issue. 